\title{
Does Wrist Arthrodesis With Structural Iliac Crest Bone Graft After Wide Resection of Distal Radius Giant Cell Tumor Result in Satisfactory Function and Local Control?
}

\author{
Tao Wang MD, Chung Ming Chan MBBS, Feng Yu MD, \\ Yuan Li MD, Xiaohui Niu MD
}

Published online: 4 January 2016

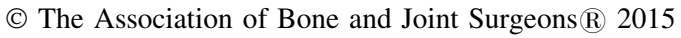

\begin{abstract}
Background Many techniques have been described for reconstruction after distal radius resection for giant cell tumor with none being clearly superior. The favored technique at our institution is total wrist fusion with autogenous nonvascularized structural iliac crest bone graft because it is structurally robust, avoids the complications associated with obtaining autologous fibula graft, and is useful in areas where bone banks are not available. However, the success of arthrodesis and the functional outcomes with this approach, to our knowledge, have only been limitedly reported.

Questions/purposes (1) What is the success of union of these grafts and how long does it take? (2) How effective is

Each author certifies that he or she, or a member of his or her immediate family, has no funding or commercial associations (eg, consultancies, stock ownership, equity interest, patent/licensing arrangements, etc) that might pose a conflict of interest in connection with the submitted article.

All ICMJE Conflict of Interest Forms for authors and Clinical Orthopaedics and Related Research ${ }^{\circledR}$ editors and board members are on file with the publication and can be viewed on request.

Each author certifies that his or her institution approved the human protocol for this investigation, that all investigations were conducted in conformity with ethical principles of research, and that informed consent for participation in the study was obtained.

This work was performed at Beijing Ji Shui Tan Hospital, Beijing, P. R. China.
\end{abstract}

T. Wang, F. Yu, Y. Li, X. Niu ( $₫)$

Department of Orthopaedic Oncology, Beijing Ji Shui Tan Hospital, Peking University, No. 31 Xin Jie Kou Dong Jie, Xi Cheng District, Beijing 100035, P. R. China

e-mail: niuxiaohui@263.net

C. M. Chan

Division of Orthopaedic Oncology, Department of Orthopaedics and Rehabilitation, University of Florida, Gainesville, FL, USA the technique in achieving tumor control? (3) What complications occur with this type of arthrodesis? (4) What are the functional results of wrist arthrodesis by this technique for treating giant cell tumor of the distal radius?

Methods Between 2005 and 2013, 48 patients were treated for biopsy-confirmed Campanacci Grade III giant cell tumor of the distal radius. Of those, 39 (81\% [39 of 48]) were treated with wrist arthrodesis using autogenous nonvascularized iliac crest bone graft. Of those, $27(69 \%$ [27 of 39]) were available for followup at a minimum of 24 months (mean, 45 months; range, 24-103 months). During that period, the general indications for this approach were Campanacci Grade III and estimated resection length of 8 $\mathrm{cm}$ or less. Followup included clinical and radiographic assessment and functional assessment using the Disabilities of the Arm, Shoulder and Hand (DASH) score, the Musculoskeletal Tumor Society (MSTS) score, grip strength, and range of motion at every followup by the treating surgeon and his team. All functional results were from the latest followup of each patient.

Results Union of the distal junction occurred at a mean of 4 months ( \pm 2 months) and union of the proximal junction occurred at a mean of 9 months ( \pm 5 months). Accounting for competing events, at 12 months, the rate of proximal junction union was $56 \%(95 \%$ confidence interval [CI], $35 \%-72 \%)$, whereas it was $67 \%(95 \% \mathrm{CI}, 45 \%-82 \%)$ at 18 months. In total, 11 of the 27 patients $(41 \%)$ underwent repeat surgery on the distal radius, including eight patients $(30 \%)$ who had complications and three $(11 \%)$ who had local recurrence. The mean DASH score was $9( \pm 7)$ (value range, 0-100, with lower scores representing better function), and the mean MSTS 1987 score was 29 ( \pm 1 ) (value range, 0-30, with higher scores representing better function) as well as $96 \%( \pm 4 \%)$ of mean MSTS 1993 score (value range, 0\%-100\%, with higher scores representing 
better function). The mean grip strength was $51 \%( \pm 23 \%)$ of the uninvolved side, whereas the mean arc of forearm rotation was $113^{\circ}\left( \pm 49^{\circ}\right)$.

Conclusions Reconstruction of defects after resection of giant cell tumor of the distal radius with autogenous structural iliac crest bone graft is a facile technique that can be used to achieve favorable functional results with complications and recurrences comparable to those of other reported techniques. We cannot show that this technique is superior to other options, but it seems to be a reasonable option to consider when other reconstruction options such as allografts are not available.

Level of Evidence Level IV, therapeutic study.

\section{Introduction}

Giant cell tumor (GCT) of bone is a locally aggressive, benign bone tumor characterized by its locally aggressive behavior and epiphyseal location and rare presence of pulmonary metastasis. The distal radius is the third most common site for GCT to occur [29], and the juxtaarticular nature of this site makes surgical management of these aggressive tumors challenging. The anatomical factors that contribute to the complexity of management of these tumors around the distal radius are the small size of the distal radius, the proximity of this site to the radiocarpal and distal radioulnar joint (DRUJ), and the relative lack of soft tissue to contain tumor breaching the cortex.

Although intralesional treatment involving extended curettage and grafting or cementation can be successfully used in Campanacci [5] Grade I and II tumors, Campanacci Grade III tumors are much more common and opinions on the best management strategy are more divergent. The distal radius is associated with a higher risk of recurrence $[4,31]$, and as such for aggressive Grade III tumors, many authors support wide en bloc resection followed by reconstruction. A wide variety of reconstructions techniques after resection of GCT of the distal radius have been described with none being clearly superior [8, 47, 48]. These differ by the type of graft replacing the resected bone and whether an attempt is made to preserve the radiocarpal articulation. The autogenous grafts described include free vascularized fibula graft $[20,25,33,35,38]$, nonvascularized fibula [6, 37, 44], vascularized structural iliac crest bone graft (ICBG) [21], nonvascularized ICBG [8], nonvascularized corticocancellous tibial struts $[11,46]$, and use of the ulna adjacent to the involved radius [36, 39]. Structural allograft $[2,41,45]$ is a popular alternative in certain countries as well. For the reconstructive technique chosen, these can be divided into those involving arthrodesis and those not. When arthrodesis is performed, this can be a total wrist arthrodesis with fixation of the native radius, the bridging graft, the carpus and a metacarpal, a total wrist arthrodesis with ulnocarpal fusion (when either ulnar centralization [39, 47] or translocation $[7,36,44]$ is performed), or a limited arthrodesis such as a fibulascapholunate arthrodesis $[3,16]$. Where arthrodesis is not performed, soft tissue reconstruction is performed to effect an osteoarticular reconstruction of the radiocarpal articulation. Certain authors describe the use of additional autogenous ICBG to fuse the DRUJ [37], whereas the addition of a distal ulna osteotomy to create a Sauve-Kapandji-type reconstruction in addition to DRUJ fusion $[22,42,43]$ has also been described.

Total wrist fusion with autogenous nonvascularized structural ICBG is one of the many reconstructive techniques and is the technique favored at the senior author's institution $(\mathrm{XN})$. This preference is based on the straightforward technique of graft harvest, the structural robustness of the graft, and the belief that ICBG would result in consistent union and fusion and stable wrist function. However, the success of arthrodesis and the functional outcomes with this approach, to our knowledge, have only been reported as a single smaller series [8].

The purpose of this study was to evaluate and present our experience with this technique and ask the following questions: (1) What is the success of union of these grafts and how long does it take? (2) How effective is the technique in achieving tumor control? (3) What complications occur with this type of arthrodesis? (4) What are the functional results of wrist arthrodesis by this technique for treating GCT of the distal radius?

\section{Patients and Methods}

Between 2005 and 2013, 48 patients were treated for biopsy-confirmed Campanacci Grade III GCT of the distal radius at the senior author's institution $(\mathrm{XN})$. Of those, 39 ( $81 \%$ [39 of 48]) were treated with wrist arthrodesis using autogenous nonvascularized ICBG. During that period, the general indications for this approach were Campanacci Grade III and estimated resection length of $8 \mathrm{~cm}$ or less. Twenty-seven (69\% [27 of 39]) were available for followup at a minimum of 24 months. We reviewed clinical information from our institution's prospectively collected musculoskeletal oncology database. Study approval was obtained from the institutional review board.

The study population included 27 individuals and comprised 11 men and 16 women. The mean age of presentation was 29 years ( \pm 7 years). Eighteen patients presented for management of the primary occurrence of the 
Table 1. Summary data of patient demographics

\begin{tabular}{|c|c|c|c|c|}
\hline Parameter & & Mean & SD & Range \\
\hline Age (years) & & 29 & 8 & $15-42$ \\
\hline $\begin{array}{l}\text { Time from treatment until las } \\
\text { followup (months) }\end{array}$ & & 45 & 20 & $24-103$ \\
\hline Parameter & Numbe & & & Percentage \\
\hline \multicolumn{5}{|l|}{ Gender } \\
\hline Male & \multicolumn{2}{|l|}{11} & \multicolumn{2}{|r|}{41} \\
\hline Female & \multicolumn{2}{|l|}{17} & \multicolumn{2}{|r|}{59} \\
\hline \multicolumn{5}{|l|}{ Laterality } \\
\hline Right & \multicolumn{2}{|l|}{10} & \multicolumn{2}{|r|}{37} \\
\hline Left & \multicolumn{2}{|l|}{17} & \multicolumn{2}{|r|}{63} \\
\hline \multicolumn{5}{|l|}{ Involvement of dominant hand } \\
\hline Yes & \multicolumn{2}{|l|}{12} & \multicolumn{2}{|r|}{44} \\
\hline No & \multicolumn{2}{|l|}{15} & \multicolumn{2}{|r|}{56} \\
\hline \multicolumn{5}{|l|}{ Primary versus recurrent disease } \\
\hline Primary & \multicolumn{2}{|l|}{18} & \multicolumn{2}{|r|}{67} \\
\hline Recurrent & \multicolumn{2}{|l|}{9} & \multicolumn{2}{|r|}{33} \\
\hline
\end{tabular}

disease, whereas nine presented with recurrent disease initially treated by curettage and bone grafting (Table 1).

All patients underwent a preoperative workup including the following: radiographs of the hand, wrist, forearm and pelvis (to make sure whether it was suitable for bone graft harvest); CT scans of the involved wrist and lung; and MRI of the involved wrist. Tissue diagnosis was confirmed by open or needle biopsy before resection and reconstruction. No adjuvant medication or radiotherapy was used in any of the patients.

The en bloc tumor resection for at least marginal margin was performed through a dorsal approach and followed by the application of autogenous nonvascularized ICBG and an osteosynthesis plate (reconstruction plate) through the same dorsal approach. A two-team approach was used for simultaneous harvesting of contralateral ICBG at the time of tumor resection with particular attention paid to preventing cross-contamination. Among the study population, the mean length of bony resection was $6 \mathrm{~cm}( \pm 0.8)$. The reconstruction was performed through a dorsal approach as well. Fixation was achieved with compression plate fixation affixing from proximal to distal: the native radius, the structural ICBG, the carpals, and the middle finger metacarpal (Fig. 1). Immobilization and weightbearing restriction of the involved wrists with forearm splints were performed postoperatively and until radiographic evidence of union was noted. However, forearm rotation was not restricted by forearm splints and permitted 4 weeks after surgery.

All patients were followed up for a minimum of 24 months. None were lost to followup. Mean followup was
45 months ( \pm 20 months; range, 24-103 months). Postoperative followup included clinical and radiographic assessment and functional assessment performed by the treating surgeon and his team. Patients were requested to report back to the clinic for followup every 3 months during the first year, 6 months at 2 to 5 years, and once a year after 5 years. The standard radiographic followup included AP and lateral plain radiographs of the wrist and forearm to assess for bony union and tumor recurrence in the bone and ultrasound scans to assess for soft tissue recurrence. Bony union was diagnosed when radiographic evidence of bony bridging was present with an absence of concerning symptoms at the site of union. Otherwise, delayed or no union was indicated when frank hardware failure and pain at the junction site with no radiographic evidence of bony union were found. Radiographs of the chest (chest CT if necessary) were performed to detect pulmonary metastases. We defined delayed union as no radiographic evidence of union within 6 months and nonunion as failure to see evidence of union for more than 12 months after the operation. The functional assessment was performed by the treating surgeon (XN, YL, FY, TW) every followup after bone union and included (1) grip strength measurement with a handgrip dynamometer and comparison to the uninvolved side; (2) photographic documentation and measurement of the arc of active forearm rotation; (3) functional scoring with Musculoskeletal Tumor Society (MSTS) scores (1987 and 1993) [9, 10]; and (4) functional scoring with Disabilities of the Arm, Shoulder and Hand (DASH) scores [15]. The functional results were reported at the latest followup only.

\section{Statistics}

We evaluated the four functional outcome measures in patient subgroups divided by a variety of independent variables including gender, side affected by disease, hand dominance, and whether they were treated for primary or recurrent disease. Descriptive statistical analysis was performed for the whole study group. Mann-Whitney U test was used to compare the functional outcomes in patients whose dominant extremity was the involved extremity versus those in whom it was not and in patients managed primarily versus for recurrent disease with significance set at $\mathrm{p}<0.05$. Spearman's correlation coefficient was calculated to evaluate for a relationship between the length of resection and reconstruction with the functional outcomes and with the time required for union of the proximal junction. Competing risk analysis by Gray's test was performed to estimate the rates of fusion of the proximal junction by calculation of the competing incidence functions of proximal junction union, hardware failure, and 

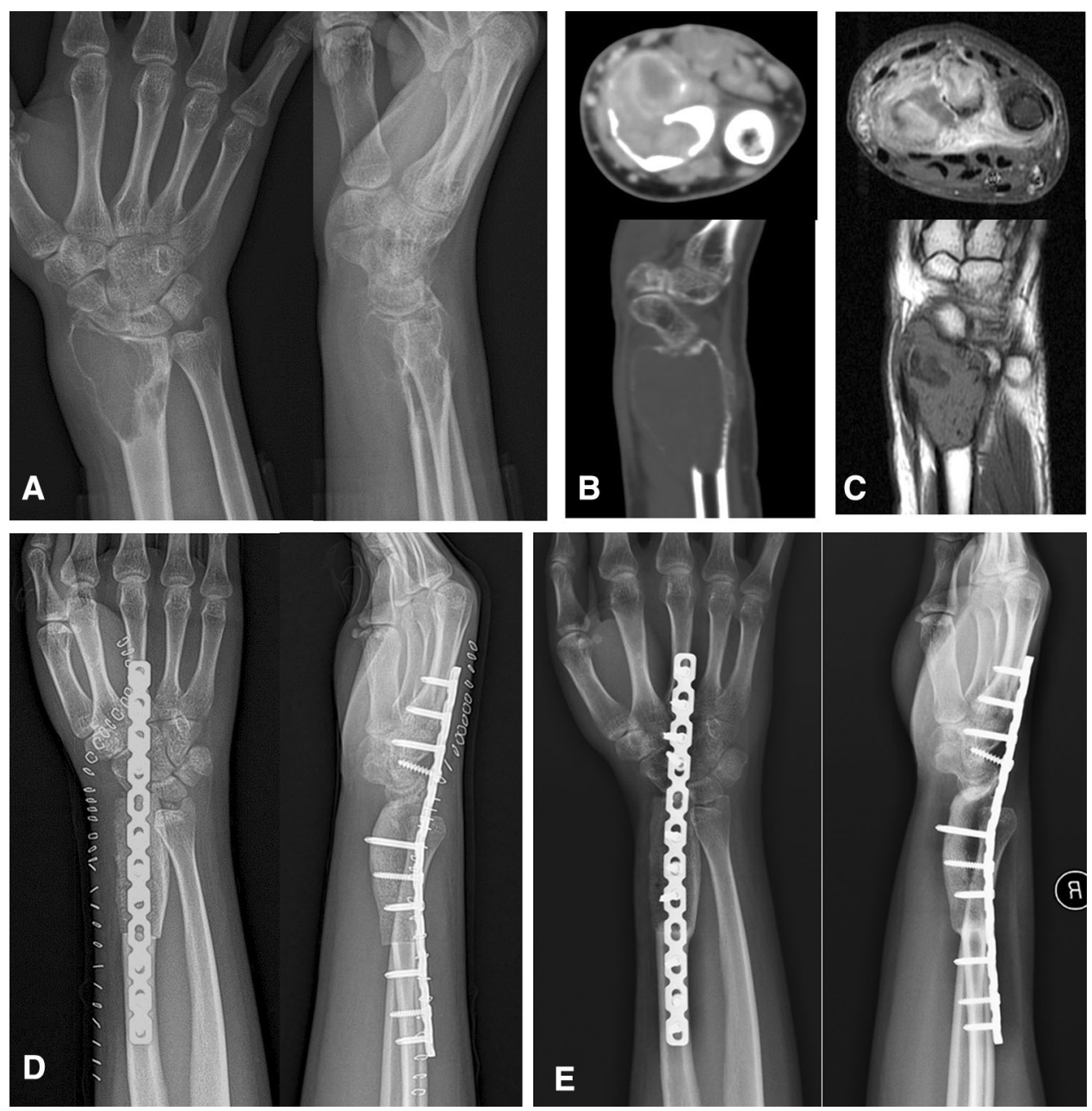

Fig. 1A-E A 25-year-old man had GCT in his distal radius on the right side. It was demonstrated in AP and lateral radiographs of the wrist (A), enhanced CT scan (B), and MRI (C) and defined as a Campanacci Grade III GCT. Postoperative AP and lateral radiographic images (D) of the forearm and wrist showed that autogenous

local recurrence. Significance was determined using a $95 \%$ confidence level. All calculations were performed using SPSS Version 22 (IBM Corp, New York, NY, USA) with the exception of the competing risk analysis, which was calculated using EZR; a statistical software package based on R (Easy R, Version 2.13.0; Jichi Medical University, Saitama, Japan) [12, 18].

\section{Results}

Union of the distal junction occurred at a mean of 4 months ( \pm 2 months). Union of the proximal junction occurred at a mean of 9 months ( \pm 5 months) (Table 2). In no patient did union of the distal junction occur after union of the structural ICBG was used for reconstruction of the defect created by resection of a distal radius involved by GCT of bone. Six months later, a bony union occurred between ICBG and host bone (metacarpal bone and radius shaft) as shown on AP and lateral radiographs of the forearm and wrist $(\mathrm{E})$.

Table 2. Summary data of clinical and functional outcomes

\begin{tabular}{lrrl}
\hline & Mean & SD & Range \\
\hline Parameter & & & \\
Resection and reconstruction length (cm) & 6 & 1 & $5-8$ \\
Time to proximal junction union (months) & 9 & 4 & $3-18$ \\
Time to distal junction union (months) & 4 & 2 & $3-12$ \\
Functional outcome & & & \\
Forearm rotational arc (degrees) & 113 & 49 & $0-160$ \\
Grip strength (percent uninvolved) & 51 & 23 & $10-99$ \\
DASH & 9 & 7 & $0-24$ \\
MSTS 1987 & 29 & 1 & $26-30$ \\
MSTS $1993(\%)$ & 96 & 4 & $87-100$ \\
\hline
\end{tabular}

DASH $=$ Disabilities of the Arm, Shoulder and Hand; MSTS = Musculoskeletal Tumor Society. 
proximal junction. Delayed or nonunion of the proximal junction occurred in six patients (21\% [six of 29]) with all undergoing reoperation. Delayed or nonunion of the distal junction did not occur in any of the patients.

Local recurrence occurred in three patients (11\% [three of 27]) at a mean of 14.3 months. All three of these patients were managed at our institution for recurrent disease. No recurrences were observed in patients treated initially by us with resection and arthrodesis by this technique. One of the three patients only had a recurrence in the soft tissue at 29 months after arthrodesis and accepted repeat tumor excision with no recurrence at latest followup. The other two had bony recurrences. One of these two patients recurred at 11 months after arthrodesis and accepted tumor resection and reconstruction by ulnar centralization. Meanwhile, she developed pulmonary metastases at 7 months and accepted resection of lung lesion at 20 months. She ultimately died of pulmonary metastases. Another one recurred at 3 months and had repeat excision of the tumor with placement of a cement spacer. Six months later, he developed another soft tissue recurrence and accepted repeat excision with no recurrence at latest followup. Three patients developed pulmonary metastases. One of these three patients developed pulmonary metastases at 7 months as mentioned previously. The other two patients developed pulmonary metastases at 7 and 40 months from surgery and were still alive with no thoracotomies to remove the pulmonary disease. All the three patients as well as all the other patients included were not treated with any neoadjuvant medication like chemotherapy, bisphosphonates, RANKL inhibitor, etc.

As a result of surgical complications, reoperations were required in eight of 27 patients (30\%). Four patients experienced hardware failure before union of the proximal junction and three underwent revision of hardware and bone grafting of the site of nonunion with the last declining further operations. One was found to have symptomatic loose hardware but had achieved bony union so this patient required hardware removal only. Two patients underwent bone grafting (at 10 and 21 months postoperatively) for delayed or nonunion without hardware failure. One patient underwent revision surgery after sustaining a fracture through the bone graft. No major complications were encountered from the donor site. The cumulative incidence functions of proximal junction union, recurrence, hardware failure, and reoperation for symptomatic nonunion were calculated and we found that at 12 months, the rate of proximal junction union was $56 \%$ (95\% confidence interval $[\mathrm{CI}], 35 \%-72 \%)$, whereas it was $67 \%(95 \%$ CI, $45 \%-82 \%)$ at 18 months (Fig. 2).

The functional outcomes of the study population were favorable. The mean DASH score was $9( \pm 7)$ (value range, $0-100$, with lower scores representing better function), and the mean MSTS 1987 scores were $29( \pm 1)$

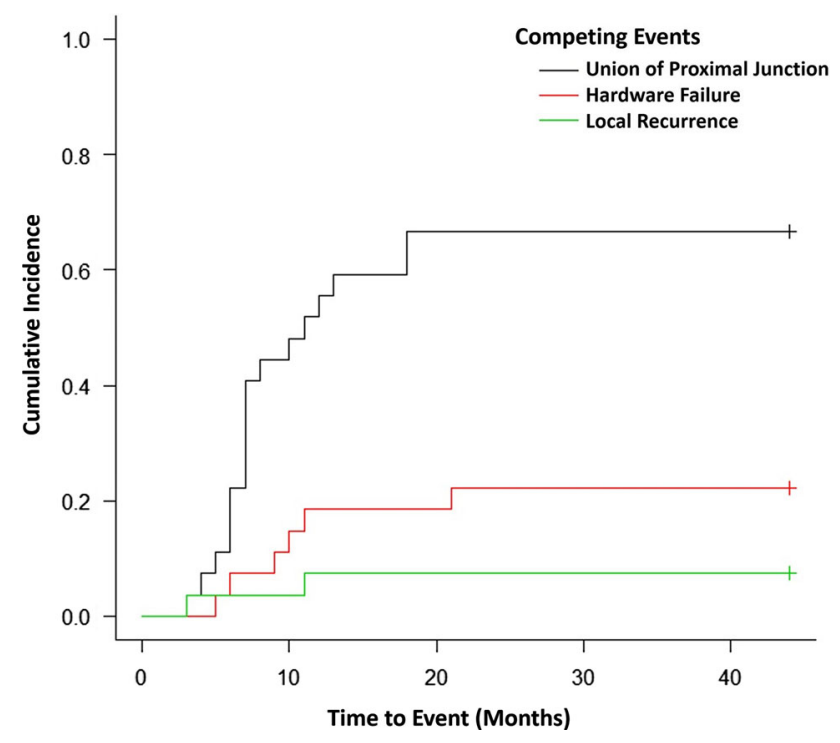

Fig. 2 The figure shows cumulative incidence of union of the proximal junction and competing events.

(value range, 0-30, with higher scores representing better function) as well as 96\% ( $\pm 4 \%)$ of mean MSTS 1993 score (value range, $0 \%-100 \%$, with higher scores representing better function). The mean grip strength was $51 \%$ $( \pm 23 \%)$ of the uninvolved side, whereas the mean arc of forearm rotation was $113^{\circ}\left( \pm 49^{\circ}\right)$. After controlling for potentially relevant confounding variables, a variety of independent variables including gender, side affected by disease, hand dominance, and whether they were treated for primary or recurrent disease was assessed. With the numbers available, only hand dominance was found to be associated with a significantly better DASH in the nondominant hand. The mean DASH was $12( \pm 8$; range, $1-$ $24)$ in the dominant hand group and $6( \pm 8$; range, $0-15)$ in the nondominant hand group $(\mathrm{p}=0.037)$. That means better DASH scores and function in the nondominant hand than those in the dominant hand. Also, recurrent disease was associated with a poorer grip strength (mean grip strength of $56 \%$ in patients managed for their first presentation versus $39 \%$ in patients managed for recurrent disease, $\mathrm{p}=$ 0.034). No other variables or outcomes were better or worse with the numbers available. We also evaluated the correlation between resection length with time for proximal union and with functional outcome measures and did not find the length of bony resection and reconstruction to be correlated with any of the functional outcome measures with the numbers available (Table 3 ).

\section{Discussion}

A wide variety of reconstruction techniques after resection of GCT of the distal radius have been described [8, 11, 21, 
Table 3. Summary of Mann-Whitney U test and Spearman's correlation tests

\begin{tabular}{|c|c|c|c|}
\hline \multicolumn{4}{|c|}{ Mann-Whitney U test of hand dominance against functional outcomes } \\
\hline \multirow[t]{2}{*}{ Outcome measure } & \multicolumn{2}{|l|}{ Mean $( \pm \mathrm{SD})$} & \multirow[t]{2}{*}{$\mathrm{p}$ value } \\
\hline & Dominant hand involved $(\mathrm{n}=12)$ & Nondominant hand involved $(\mathrm{n}=15)$ & \\
\hline Forearm rotational arc (degrees) & $101( \pm 58)$ & $123( \pm 39)$ & 0.432 \\
\hline Grip strength ( $\%$ of uninvolved side) & $56( \pm 23)$ & $46( \pm 24)$ & 0.374 \\
\hline MSTS 1993 & $94 \%( \pm 5 \%)$ & $98 \%( \pm 3 \%)$ & 0.083 \\
\hline DASH & $12( \pm 8)$ & $6( \pm 4)$ & 0.037 \\
\hline \multicolumn{4}{|c|}{ Mann-Whitney U test of hand dominance against functional outcomes } \\
\hline \multirow[t]{2}{*}{ Outcome measure } & \multirow{2}{*}{\multicolumn{2}{|c|}{$\begin{array}{l}\text { Mean }( \pm \mathrm{SD}) \\
\text { Primary }(\mathrm{n}=18)\end{array}$}} & \multirow[t]{2}{*}{$\mathrm{p}$ value } \\
\hline & & & \\
\hline Forearm rotational arc (degrees) & $122( \pm 41)$ & $96( \pm 61)$ & 0.339 \\
\hline Grip strength ( $\%$ of uninvolved side) & $56( \pm 18)$ & $39( \pm 30)$ & 0.034 \\
\hline MSTS 1993 & $97 \%( \pm 4 \%)$ & $94 \%( \pm 3 \%)$ & 0.095 \\
\hline DASH & $8( \pm 7)$ & $10( \pm 6)$ & 0.348 \\
\hline \multicolumn{4}{|c|}{ Spearman's correlation of length of resection against outcomes/time to proximal junction union } \\
\hline \multicolumn{2}{|l|}{ Factor tested } & Correlation coefficient & \\
\hline \multicolumn{2}{|l|}{ Forearm rotational arc } & 0.07 & \\
\hline \multicolumn{2}{|l|}{ Grip strength } & 0.33 & \\
\hline \multicolumn{2}{|l|}{ DASH } & 0.19 & \\
\hline \multicolumn{2}{|l|}{ MSTS 1993} & 0.33 & \\
\hline \multicolumn{2}{|l|}{ Time to proximal junction union } & 0.89 & \\
\hline
\end{tabular}

MSTS = Musculoskeletal Tumor Society; DASH = Disabilities of the Arm, Shoulder and Hand.

$22,25,36-40,47,48]$. We began to use total wrist fusion with nonvascularized, autogenous structural ICBG for this indication because graft harvest is straightforward, the graft is structurally robust, and we believed that the autogenous graft source would result in consistent osseous union. We also believed that total wrist fusion avoided issues of DRUJ and wrist instability and the risk of developing joint degeneration. However, the success of arthrodesis and the functional outcomes with this approach, to our knowledge, have only had limited reports in the literature [8]. Here, we found that union occurred in all patients, but reoperations were common; local recurrence was uncommon and limited to patients whose wrist arthrodesis was performed for recurrent GCT (we saw no recurrences in patients whose fusions were performed at the time of the initial GCT resection). Functional results, including DASH and MSTS scores, generally were good.

There were several limitations to our study. (1) It was retrospective and with $34 \%$ of patients lost to followup before 24 months, we had a relatively small group of patients to assess. In China, although most of the patients treated in our institution tended to come back for followup, some of them came back to their surgeon only when they noted a complication or tumor relapse. Those who have no complications or tumor relapse after bone union were not willing to visit the clinic because they thought they had been cured completely and it was unnecessary to do so. Under these circumstances, most of our patients who were lost to followup were event-free for 2 years or more. (2) We did not compare these results with other reconstruction techniques so we cannot claim that our results are better or worse than other options listed in the introduction. (3) We cannot comment on donor site morbidity because we did not routinely ask patient specifically about the presence of symptoms of common minor complications related to iliac crest bone harvesting such as persistent donor site pain or thigh numbness and only self-reported symptoms of complications were recorded. (4) Lastly, we could not show that there were other techniques or patient-derived factors that affected functional results except for handedness presumably resulting from insufficient numbers of patients. It should also be noted that the DASH assessment used was a translation of the questionnaire, which had not be formally validated. There is also the possibility of differences in 
cultural acceptance in expressing dissatisfaction in reporting disability or with coping with disability that might have resulted in underreporting of disability by patients in our study. This is beyond the scope of our study but might be an area worthy of further study.

We found that we achieved union at both osteosynthesis sites by 9 months in $67 \%$ of our patients (18 of 27). All delayed or nonunions were in the proximal osteosynthesis site and all required a second operation to achieve union. Some of our complications might relate to using a reconstruction plate, which was the only option available to use during the time of this study. Since 2013 we have been using a more substantial locking compression plate and we hope that this will lead to fewer hardware-related complications. Considering the epiphyseal location of most GCT of bone, the length of the involved bone resected is relatively short compared with other bone tumors (such as primary bone malignancy). As such the defects created are particularly amenable to reconstruction with autogenous structural ICBG. Some authors favor the use of vascularized fibula grafts for the benefits of prompt bony union, the option to include skin to address soft tissue defects, and durability of the reconstruction [8, 25, 34]. On the other hand, the use of nonvascularized fibular grafts has the advantage of being less technically demanding. When longer defects have to be reconstructed, the use of fibula graft or allograft may offer an advantage over ICBG. Harvesting of autogenous fibula is not without risk and complications [26] including foot drop, painful neuromas, ankle instability [28] and ankle valgus deformity [27]. The use of nonvascularized ICBG for reconstruction of postresection defects of the distal radius has several advantages over some of the other techniques described. The technique of harvesting the graft is straightforward and familiar to orthopaedic and hand surgeons. The donor site morbidity is acceptable and arguably lower than that from harvesting of autogenous fibula. Furthermore, obtaining additional cancellous graft from the iliac crest to augment the wrist fusion site is convenient. ICBG harvesting is associated with some complications [1, 24], including meralgia paresthetica, persistent pain at the harvest site, fracture [30], and hernia [48]. Attention to good technique may minimize the risk of complications, and no donor siterelated major complications were reported by our study population, but we did not specifically ask the patients about this.

A total of $11 \%$ (three of 27) of our patients experienced a local recurrence, which is comparable to that published in other studies and analyzed in recent meta-analyses [23, 34]. In contrast, local recurrence after intralesional excision is as high as $31 \%$ [23, 34]. In a series of 15 patients with Grade III GCT of the distal radius, Kang et al. [19] used limited intralesional excision and cementation for nine patients with limited volar cortical involvement that was contained by the overlying pronator quadratus; $22 \%$ of them experienced recurrences.

Major complications occurred in 30\% (eight of 27) of our patients, including six patients who underwent reoperation for nonunion or symptomatic delayed union of the proximal junction, one who developed hardware loosening, and one who developed fracture of the graft. This is comparable to other studies that have reported complications in $22 \%$ to $100 \%$ of their patients when resection was the mode of treatment [8, 14, 40, 47]. The higher risk of complications with wide resections as compared with intralesional is a reason to consider intralesional treatment when technically feasible, however, in Grade III disease that is limited to select cases and is accompanied by a higher likelihood of local recurrence. A particular caution when using this technique (or any of the other techniques using harvesting autogenous graft) is the known risk of iatrogenic seeding of the bone graft donor site. The phenomenon of direct seeding of GCT is well known [13, 17, 32], and the surgeon and his or her entire team should accordingly pay special attention to preventing cross-contamination. In this study, a two-team approach using separate instruments was used to prevent cross-contamination; in addition to this, the bone graft was harvested from the contralateral iliac crest further separating the surgical fields.

The restoration of the best possible function is the primary goal of any postresection reconstruction technique. The functional scores of patients in our study were favorable, and this was similarly found in the study by Clarkson et al. [8]. In that study, no difference was noted between their groups that underwent reconstruction with ICBG and vascularized fibula graft, and they hypothesized that this may have been the result of the ceiling effect because both groups faired favorably. In our study, functional scores were similar in patients who were operated on their dominant or nondominant hand and for patients presenting for their first presentation or recurrent disease. This may similarly reflect a ceiling effect with most patients reporting very favorable functional results. The sole exception was DASH scores being higher (12 versus 6) in patients who had their dominant hand involved. This is understandable because the reduction in strength and ROM in their dominant hand likely adds more inconvenience in their daily life than when the nondominant wrist is fused.

In conclusion, reconstruction of defects after resection of aggressive GCT of the distal radius with autogenous nonvascularized structural ICBG is a reconstruction option that appears to achieve satisfactory local control and favorable functional results. Although there are many options for the surgeon to consider, this technique avoids the need of a bone bank, is less technically challenging 
than techniques such as free fibular transfers, and complications appear comparable to those of other described techniques [6, 11, 44, 47]. With only $66 \%$ of eligible patients followed up for 2 years of more, our results do not include potential complications or poor outcomes in patients who did not return and may only represent the best case scenario for this technique. So, the results in our study are considered preliminary and we cannot claim superiority of this reconstruction over other approaches. However, if our findings are substantiated by larger studies that have longer and more complete followup are completed, we believe this technique is a more reasonable alternative for the reconstruction of defect after tumor resection of GCT of the distal radius.

\section{References}

1. Arrington ED, Smith WJ, Chambers HG, Bucknell AL, Davino NA. Complications of iliac crest bone graft harvesting. Clin Orthop Relat Res. 1996;329:300-309.

2. Bianchi G, Donati D, Staals EL, Mercuri M. Osteoarticular allograft reconstruction of the distal radius after bone tumour resection. J Hand Surg Br. 2005;30:369-373.

3. Bickert B, Heitmann C, Germann G. Fibulo-scapho-lunate arthrodesis as a motion-preserving procedure after tumour resection of the distal radius. J Hand Surg Br. 2002;27:573-576.

4. Blackley HR, Wunder JS, Davis AM, White LM, Kandel R, Bell RS. Treatment of giant-cell tumors of long bones with curettage and bone-grafting. J Bone Joint Surg Am. 1999;81:811-820.

5. Campanacci M. Giant cell tumor and chondrosarcoma: grading, treatment and results. Cancer Res. 1976;54:257-261.

6. Chadha M, Arora SS, Singh AP, Gulati D, Singh AP. Autogenous non-vascularized fibula for treatment of giant cell tumor of distal end radius. Arch Orthop Trauma Surg. 2010;130:1467-1473.

7. Chalidis BE, Dimitriou CG. Modified ulnar translocation technique for the reconstruction of giant cell tumor of the distal radius. Orthopedics. 2008;31:608.

8. Clarkson PW, Sandford K, Phillips AE, Pazionis TJ, Griffin A, Wunder JS, Ferguson PC, Masri BA, Goetz T. Functional results following vascularized versus nonvascularized bone grafts for wrist arthrodesis following excision of giant cell tumors. $J$ Hand Surg Am. 2013;38:935-940.

9. Enneking WF. Modification of the system for functional evaluation in the surgical management of musculoskeletal tumours. In: Enneking WF, ed. Limb Salvage in Musculoskeletal Oncology. New York, NY, USA: Churchill Livingstone; 1987:626-639.

10. Enneking WF, Dunham W, Gebhardt MC, Malawar M, Pritchard DJ. A system for the functional evaluation of reconstructive procedures after surgical treatment of tumors of the musculoskeletal system. Clin Orthop Relat Res. 1993;286:241-246.

11. Flouzat-Lachaniette CH, Babinet A, Kahwaji A, Anract P, Biau DJ. Limited arthrodesis of the wrist for treatment of giant cell tumor of the distal radius. J Hand Surg Am. 2013;38:1505-1512.

12. Gray RJ. A class of k-sample tests for comparing the cumulative incidence of a competing risk. Ann Stat. 1988;16:1141-1154.

13. Gulia A, Puri A, Salunke A, Desai S, Jambhekar NA. Iatrogenic implantation of giant cell tumor at bone graft donor site and clinical recommendations to prevent 'a rare avoidable complication.’ Eur J Orthop Surg Traumatol. 2013;23:715-718.
14. Harness NG, Mankin HJ. Giant-cell tumor of the distal forearm. $J$ Hand Surg Am. 2004;29:188-193.

15. Hudak PL, Amadio PC, Bombardier C. Development of an upper extremity outcome measure: the DASH (Disabilities of the Arm, Shoulder, and Hand) [corrected]. The Upper Extremity Collaborative Group (UECG). Am J Ind Med. 1996;29:602-608.

16. Jaminet P, Rahmanian-Schwarz A, Pfau M, Nusche A, Schaller HE, Lotter O. Fibulo-scapho-lunate arthrodesis after resection of the distal radius for giant-cell tumor of the bone. Microsurgery. 2012;32:458-462.

17. Joynt GH, Ortved WE. The accidental operative transplantation of benign giant cell tumor. Ann Surg. 1948;127:1232-1239.

18. Kanda Y. Investigation of the freely available easy-to-use software 'EZR' for medical statistics. Bone Marrow Transplant. 2013;48:452-458.

19. Kang L, Manoso MW, Boland PJ, Healey JH, Athanasian EA. Features of grade 3 giant cell tumors of the distal radius associated with successful intralesional treatment. J Hand Surg Am. 2010;35:1850-1857.

20. Lehner B, Jung M, von Stillfried F. [Total wrist fusion with vascularized fibula graft after tumor resection of the distal radius] [in German]. Oper Orthop Traumatol. 2012;24:186-195.

21. Leung PC, Chan KT. Giant cell tumor of the distal end of the radius treated by the resection and free vascularized iliac crest graft. Clin Orthop Relat Res. 1986;202:232-236.

22. Li J, Jiao Y, Guo Z, Ji Ch, Wang Z. Comparison of osteoarticular allograft reconstruction with and without the Sauvé-Kapandji procedure following tumour resection in distal radius. J Plast Reconstr Aesthet Surg. 2015;68:995-1002.

23. Liu YP, Li KH, Sun BH. Which treatment is the best for giant cell tumors of the distal radius? A meta-analysis. Clin Orthop Relat Res. 2012;470:2886-2894.

24. Loeffler BJ, Kellam JF, Sims SH, Bosse MJ. Prospective observational study of donor-site morbidity following anterior iliac crest bone-grafting in orthopaedic trauma reconstruction patients. J Bone Joint Surg Am. 2012;94:1649-1654.

25. Muramatsu K, Ihara K, Azuma E, Orui R, Goto Y, Shigetomi M, Doi K. Free vascularized fibula grafting for reconstruction of the wrist following wide tumor excision. Microsurgery. 2005;25:101-106.

26. Nassr A, Khan MH, Ali MH, Espiritu MT, Hanks SE, Lee JY, Donaldson WF, Kang JD. Donor-site complications of autogenous nonvascularized fibula strut graft harvest for anterior cervical corpectomy and fusion surgery: experience with 163 consecutive cases. Spine J. 2009;9:893-898.

27. Nathan SS, Athanasian E, Boland PJ, Healey JH. Valgus ankle deformity after vascularized fibular reconstruction for oncologic disease. Ann Surg Oncol. 2009;16:1938-1945.

28. Nathan SS, Hung-Yi L, Disa JJ, Athanasian E, Boland P, Cordeiro PG, Healey JH. Ankle instability after vascularized fibular harvest for tumor reconstruction. Ann Surg Oncol. 2005;12:5764.

29. Niu X, Zhang Q, Hao L, Ding Y, Li Y, Xu H, Liu W. Giant cell tumor of the extremity: retrospective analysis of 621 Chinese patients from one institution. J Bone Joint Surg Am. 2012;94:461-467.

30. Nocini PF, Bedogni A, Valsecchi S, Trevisiol L, Ferrari F, Fior A, Saia G. Fractures of the iliac crest following anterior and posterior bone graft harvesting. Review of the literature and case presentation. Minerva Stomatol. 2003;52:441-452.

31. O’Donnell RJ, Springfield DS, Motwani HK, Ready JE, Gebhardt MC, Mankin HJ. Recurrence of giant-cell tumors of the long bones after curettage and packing with cement. J Bone Joint Surg Am. 1994;76:1827-1833. 
32. Ofluoglu O, Donthineni R. Iatrogenic seeding of a giant cell tumor of the patella to the proximal tibia. Clin Orthop Relat Res. 2007;465:260-264.

33. Ono H, Yajima H, Mizumoto S, Miyauchi Y, Mii Y, Tamai S. Vascularized fibular graft for reconstruction of the wrist after excision of giant cell tumor. Plast Reconstr Surg. 1997;99:10861093.

34. Pazionis TJ, Alradwan H, Deheshi BM, Turcotte R, Farrokhyar F, Ghert M. A systematic review and meta-analysis of en-bloc vs intralesional resection for giant cell tumor of bone of the distal radius. Open Orthop J. 2013;7:103-108.

35. Pho RW. Free vascularised fibular transplant for replacement of the lower radius. J Bone Joint Surg Br. 1979;61:362-365.

36. Puri A, Gulia A, Agarwal MG, Reddy K. Ulnar translocation after excision of a Campanacci grade-3 giant-cell tumour of the distal radius: an effective method of reconstruction. J Bone Joint Surg Br. 2010;92:875-879.

37. Saini R, Bali K, Bachhal V, Mootha AK, Dhillon MS, Gill SS. En bloc excision and autogenous fibular reconstruction for aggressive giant cell tumor of distal radius: a report of 12 cases and review of literature. J Orthop Surg Res. 2011;6:14.

38. Scaglioni MF, Chang EI, Gur E, Barnea Y, Meller I, Kollander Y, Bickels J, Dadia S, Zaretski A. The role of the fibula head flap for joint reconstruction after osteoarticular resections. J Plast Reconstr Aesthet Surg. 2014;67:617-623.

39. Seradge H. Distal ulnar translocation in the treatment of giant-cell tumors of the distal end of the radius. J Bone Joint Surg Am. 1982;64:67-73.

40. Sheth DS, Healey JH, Sobel M, Lane JM, Marcove RC. Giant cell tumor of the distal radius. J Hand Surg Am. 1995;20:432-440.
41. Smith RJ, Mankin HJ. Allograft replacement of distal radius for giant cell tumor. J Hand Surg Am. 1977;2:299-308.

42. Szabo RM, Anderson KA, Chen JL. Functional outcome of en bloc excision and osteoarticular allograft replacement with the Sauve-Kapandji procedure for Campanacci grade 3 giant-cell tumor of the distal radius. J Hand Surg Am. 2006;31:1340-1348.

43. Szabo RM, Thorson EP, Raskind JR. Allograft replacement with distal radioulnar joint fusion and ulnar osteotomy for treatment of giant cell tumors of the distal radius. J Hand Surg Am. 1990;15:929-933.

44. Taraz-Jamshidi MH, Gharadaghi M, Mazloumi SM, HallajMoghaddam M, Ebrahimzadeh MH. Clinical outcome of enblock resection and reconstruction with nonvascularized fibular autograft for the treatment of giant cell tumor of distal radius. $J$ Res Med Sci. 2014;19:117-121.

45. Urabe K, Naruse K, Uchino M, Takaso M, Fujita M, Uchiyama $\mathrm{K}$, Okada T, Kasahara M, Itoman M. The expense for one implantation of a banked bone allograft from a cadaveric donor and the issues affecting current advanced medical treatment in the Japanese orthopaedic field. Cell Tissue Bank. 2009;10:259-265.

46. van de Sande MA, van Geldorp NH, Dijkstra PD, Taminiau AH. Surgical technique: Tibia cortical strut autograft interposition arthrodesis after distal radius resection. Clin Orthop Relat Res. 2013:471:803-813.

47. Vander Griend RA, Funderburk $\mathrm{CH}$. The treatment of giant-cell tumors of the distal part of the radius. J Bone Joint Surg Am. 1993;75:899-908.

48. Velchuru VR, Satish SG, Petri GJ, Sturzaker HG. Hernia through an iliac crest bone graft site: report of a case and review of the literature. Bull Hosp Jt Dis. 2006;63:166-168. 